\title{
Identifikasi Sesar di Wilayah Gorontalo dengan Analisis Mekanisme Bola Folkus
}

\author{
Nurfitriania,b*, Guntur Pasaua, Slamet Suyitno Raharjo ${ }^{b}$ \\ aJurusan Fisika, FMIPA, Unsrat, Manado \\ ${ }^{b} B a d a n$ Meteorologi Klimatologi dan Geofisika
}

\begin{tabular}{l}
\hline K A T A K U N C I \\
\hline Mekanisme bola fokus \\
Sesar \\
Rupture
\end{tabular}

\begin{tabular}{l}
\hline KEY W O R D S \\
\hline Focal Mechanism \\
Fault \\
Rupture
\end{tabular}

\begin{tabular}{l}
\hline AVAILABLE ONLINE \\
\hline 25 Februari 2014 \\
\hline
\end{tabular}

\begin{abstract}
A B S TR A K
Gorontalo menjadi salah satu daerah rawan bencana gempa bumi dan ecara tektonik berada di wilayah pertemuan 2 lempeng besar, yakni lempeng Pasifik dan Eurasia serta lempeng-lempeng mikro. Peta Geologi Gorontalo menunjukkan adanya struktur sesar yang memotong wilayah kota Gorontalo. Adapun tujuan penelitian ini adalah mengidentifikasi keberadaan struktur sesar di wilayah Gorontalo dengan menggunakan metode mekanisme bola fokus kejadian gempa bumi di wilayah daratan Gorontalo periode 1963-2013 dengan sumber data dari katalog gempa bumi USGS, Global Centroid Momen Tensor, dan BMKG. Analisis bola fokus menunjukkan adanya 3 daerah dugaan sesar aktif, dengan tipe sesar cenderung oblique, dengan panjang $24,54 \mathrm{~km}$ sampai $27,54 \mathrm{~km}$ dan lebar rupture $8,51 \mathrm{~km}$ sampai $9,22 \mathrm{~km}$. Hasil analisis ini juga mendeteksi adanya satu daerah dugaan sesar aktif yang tidak teridentifikasi pada peta geologi.
\end{abstract}

\begin{tabular}{l}
\hline A B S T R A C T \\
\hline Gorontalo is one of the earthquake prone areas and is tectonically located \\
at the junction of two major plates and some microplates. Geological map \\
indicated the presence of fault structures across Gorontalo. This study was \\
aimed to identify the presence of fault structures in the Gorontalo area \\
using focal mechanism of earthquakes in the mainland region of \\
Gorontalo at the period of $1963-2013$ with data sourced from the USGS \\
earthquake catalog, the Global Centroid Moment Tensor, and BMKG. The \\
analysis showed that there were 3 suspected active fault area having \\
oblique-type fault with length of 24,54 to $27,54 \mathrm{~km}$ and rupture width of \\
8,51 to $9,22 \mathrm{~km}$. The analysis also detected the presence of a suspected \\
active fault area which was not identified on the geological map.
\end{tabular}

\section{Pendahuluan \\ Pulau Sulawesi terletak pada zona pertemuan di antara tiga pergerakan lempeng besar yang bertemu secara konvergen Konvergensi ini menimbulkan pengembangan semua jenis struktur di semua skala, termasuk subduksi dan zona tumbukan, sesar dan thrust (Pasau dan Tanauma, 2011).}

Gorontalo menjadi salah satu daerah yang rawan akan bencana gempa bumi. Secara geologi
(Gambar 1) terdapat struktur sesar yang memotong wilayah kota Gorontalo serta melintasi danau Limboto. Kajian tentang struktur sesar ini belum banyak dilakukan.

Belajar dari pengalaman gempa Yogyakarta tanggal 27 Mei 2008 dengan episenter di darat dan kedalaman dangkal, diperkirakan akibat aktivitas sesar lokal (Abidin et al, 2009) telah menimbulkan korban jiwa dan kerusakan infrastruktur yang cukup besar, maka ancaman yang sama di wilayah yang terindikasi memiliki struktur sesar aktif akan selalu 
mengintai, maka perlu dilakukan kajian yang lebih mendalam untuk mengurangi ancaman ini. Untuk mengetahui keberadaan struktur geologi tersebut, maka dibutuhkan upaya untuk merekonstruksi struktur sesar ini menggunakan metode lain.

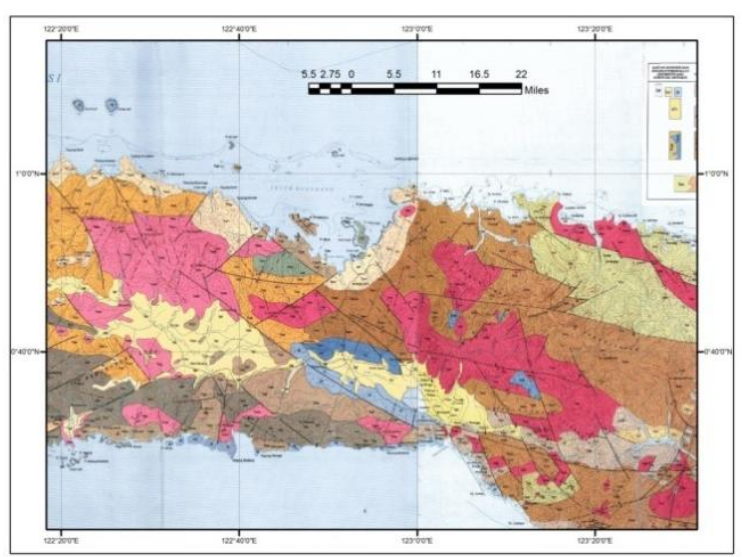

Gambar 1. Peta Geologi Gorontalo (Sumber: Peta Geologi Lembar Tilamuta, Sulawesi (2216), (Bachri et al, 1993) dan Peta Geologi Lembar Kotamobagu, Sulawesi (2316), (Apandi et al, 1997))

Secara khusus, gempa-gempa yang terjadi pada sesar yang teridentifikasi dari peta geologi. Gelombang seismik yang diradiasikan dari sumber gempa merefleksikan geometri dari sesar dan pergerakan sesar itu sendiri selama terjadi rupture, yang artinya gelombang sesismik dapat digunakan untuk mendapatkan kinematika dari sesar dengan menggunakan metode mekanisme fokus (Afnimar, 2009).

\section{Metode}

Dalam penelitian ini data yang digunakan adalah data sekunder berupa data kejadian gempa bumi dari tahun 1963-2013 yang berasal dari katalog gempa bumi USGS, Global Centroid Moment Tensor (Global CMT), dan Badan Meteorologi Klimatologi dan Geofisika (BMKG).

Data gempa yang dianalisis berupa data kejadian gempa bumi dengan episenter di darat dengan batas daerah penelitian yaitu pada koordinat $0^{\circ} \mathrm{LU}-1.5^{\circ} \mathrm{LU}$ dan $122^{\circ}$ BT-123.5 ${ }^{\circ} \mathrm{BT}$. Parameter data gempa bumi yang digunakan dalam penelitian ini adalah berupa lokasi episenter (sumber gempa bumi), magnitudo, dan kedalaman sumber gempa bumi serta parameter bola fokus berupa data polarisasi awal gelombang gempa pada stasiun pengamat. Metode penelitian yang digunakan dalam penelitian ini adalah metode analisis deskriptif.

\section{Hasil dan Pembahasan}

\subsection{Pemetaan Penampang Melintang Sebaran Episenter di Sulawesi Utara}

Langkah awal dalam identifikasi keberadaan sesar dimulai dengan membuat garis penampang AA' (Gambar 2) yang melintang barat laut-tenggara yang melewati zona subduksi dan zona patahan
Gorontalo yang ditunjukkan oleh peta geolog Gorontalo (Gambar 1). Cakupan wilayah garis penampang ini sepanjang $241 \mathrm{~km}$.

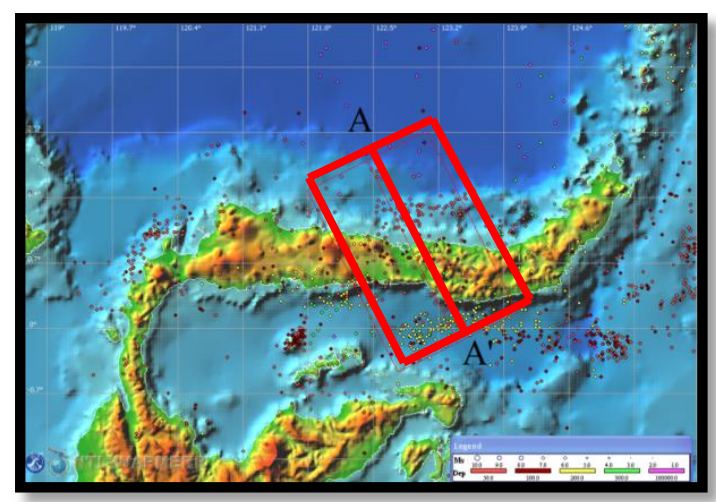

Gambar 2. Garis penampang A-A

Profil penampang A-A' (Gambar 3) menunjukkan bahwa wilayah bagian utara didominasi dengan gempa dengan kedalaman dangkal, kemudian bergerak ke tenggara, kedalaman episenter gempa menjadi menengah dan di bagian selatan ditemui gempa-gempa dalam yang cukup dominan. Garis kuning pada Gambar 3 menunjukkan pola sebaran episenter terhadap kedalaman yang dicurigai akibat aktivitas subduksi lempeng Sangihe di sebelah utara pulau Sulawesi. Di wilayah daratan Gorontalo ditemui adanya gempa-gempa sangat dangkal yang di sekitarnya terdapat gempa-gempa dengan kedalaman menengah sampai dalam akibat aktivitas subduksi. Gempa-gempa dangkal yang berada pada lingkaran merah (Gambar 3) inilah yang diduga akibat aktivitas sesar.

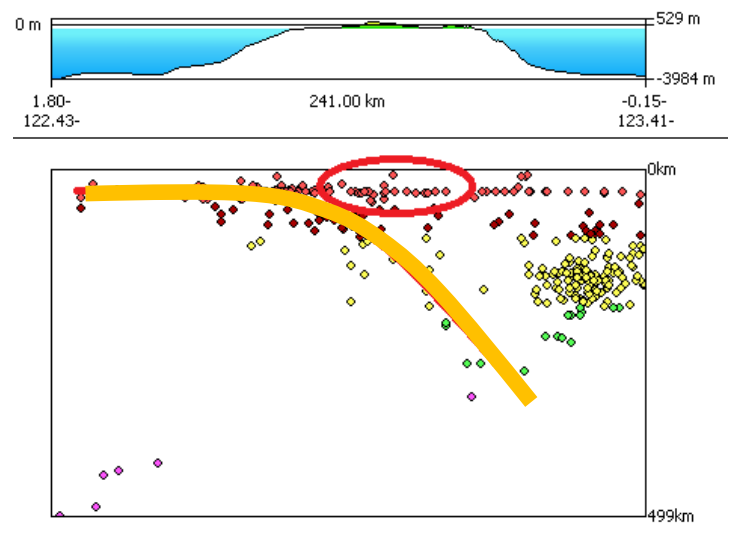

Gambar 3. Profil Garis Penampang A-A' terhadap kedalaman

\subsection{Mekanisme Bola Fokus}

Mekanisme bola fokus ini dapat menggambarkan kinematika sesar suatu sumber gempa, berupa tipe sesar, arah jurus sesar, arah sudut dip, dan sudut rake suatu sumber gempa. Data impuls awal gelombang $P$ dari berbagai stasiun pengamat dan posisi lintang dan bujur stasiun pengamat diproses menggunakan bantuan software AZMTAK. 


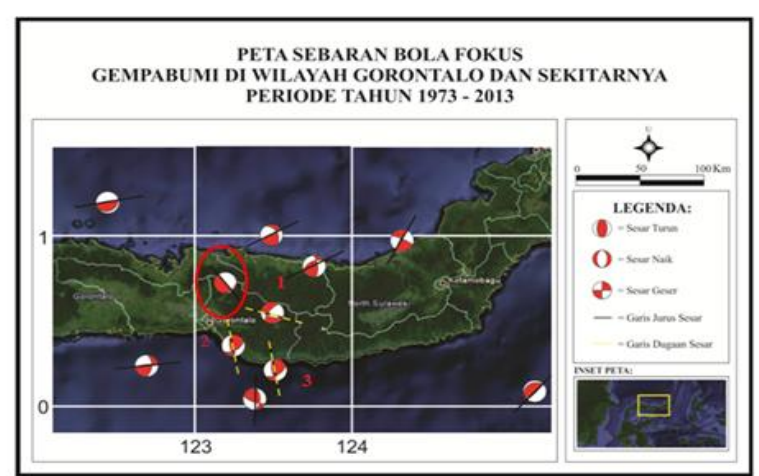

Gambar 4. Peta sebaran Bola Fokus Gempa Bumi di Wilayah Gorontalo beserta dugaan sesar periode 1973-2013

Jika ditinjau dari arah strike bola fokus gempa bumi di wilayah ini, tampak adanya struktur sesar yang berkesesuaian dengan peta geologi wilayah Gorontalo. Dugaan sesar ini ditunjukkan oleh garis putus-putus berwarna kuning pada Gambar 4. Di bagian tengah daratan Gorontalo terdapat sesar yang mengarah barat laut- tenggara dengan jenis patahan kombinasi antara sesar turun dan sesar geser atau oblique (sesar 1 pada gambar 4). Sementara di daratan Gorontalo sebelah selatan, terdapat dua bola fokus yang menunjukkan arah strike cenderung utara-selatan dengan tipe patahan oblique (sesar 2 dan 3 pada gambar 4), yakni kombinasi antara sesar naik dengan sesar mendatar.

\subsection{Perhitungan Panjang dan Lebar Rupture Sesar}

Dengan menggunakan software analisis Zmap diperoleh kontur sebaran nilai-a dan nilai-b di wilayah Gorontalo (Gambar 5 dan 6).

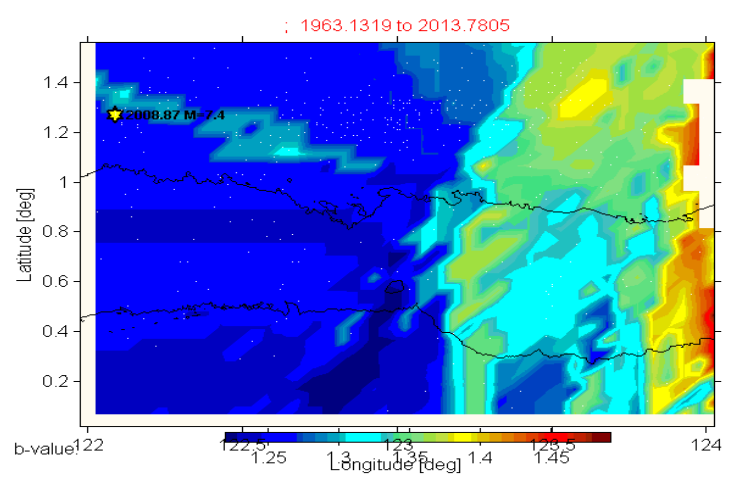

Gambar 5. Kontur Distribusi Nilai b Wilayah Gorontalo.

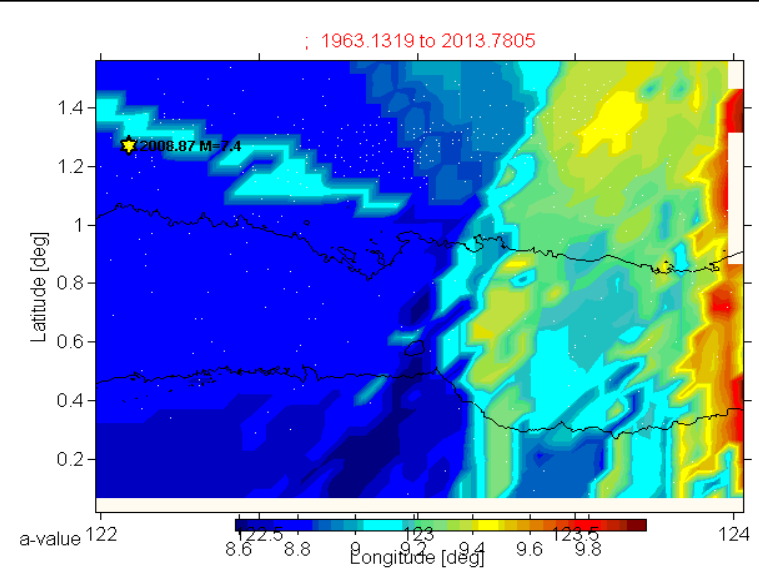

Gambar 6. Kontur Distribusi Nilai a Wilayah Gorontalo.

Dengan Kurva Distribusi Frekwensi-Magnitudo wilayah Gorontalo berdasarkan katalog USGS 1963Oktober 2013. Slope dari garis menyatakan relasi Guttenberg-Richter Log N=a-bM (Gambar 7).

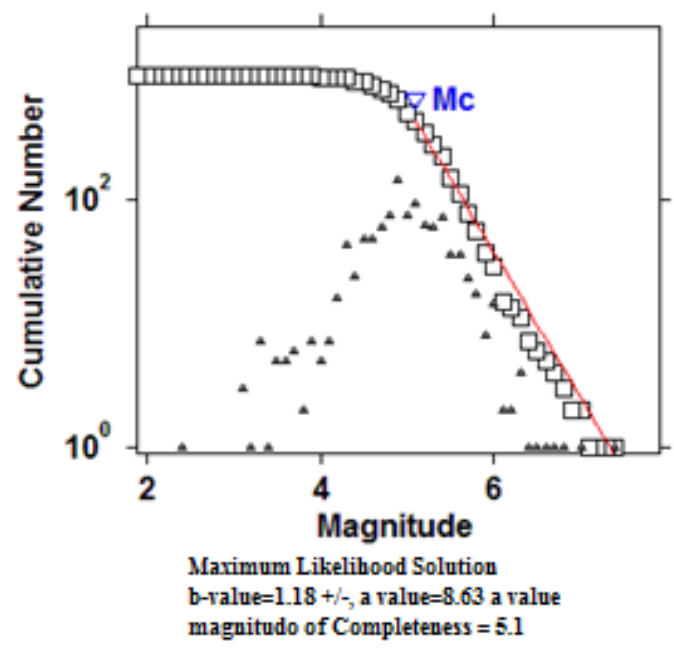

Gambar 7. Kurva Distribusi Frekwensi Magnitudo Wilayah Gorontalo periode 1963-2013 (Sumber:Katalog USGS).

Dari hasil pengolahan Zmap pada wilayah dugaan sesar 1 menunjukkan nilai a sebesar 9.4, nilai $b$ sebesar 1.38 dengan Magnitudo Completeness (Mc) sebesar 5.1. Dengan menggunakan perumusan Empiris GuttenbergRichter, $\log N=a-b M$ (Ibrahim et al, 2005), sehingga diperoleh magnitudo maksimum di wilayah Gorontalo sebesar 6.8 Mw. Untuk daerah dugaan sesar 2 diperoleh nilai $a=9.4$ dan nilai $b=1,35$ dengan nilai magnitude maksimum sebesar 6.9 Mw. Sementara untuk daerah dugaan sesar 3 diperoleh nilai $a=9.1$ dan nilai $b=1,325$ dengan nilai magnitude maksimum sebesar $6.8 \mathrm{Mw}$

Dari hasil hasil perhitungan numerik sesar menggunakan pendekatan empiris (Wells dan Coopersmith, 1994) diperoleh hasil panjang sesar yang terbentuk di wilayah Gorontalo sepanjang $24.54 \mathrm{~km}$ untuk estimasi magnitudo 6.8 Mw untuk 
wilayah sesar 1 dan 3, sedangkan untuk lebar rupture sesar diperoleh $8.51 \mathrm{~km}$ untuk estimasi magnitudo maksimum yang sama. Sementara untuk sesar 2 diperoleh panjang sesar $27.54 \mathrm{~km}$ dan lebar rupture $9.22 \mathrm{~km}$.

\section{Kesimpulan}

Berdasarkan hasil analisis mekanisme bola fokus kejadian gempa bumi di wilayah Gorontalo, ditemukan 3 daerah dugaan sesar aktif secara seismik yang memiliki kesesuaian dengan peta Geologi wilayah Gorontalo. Daerah dugaan sesar 1 memiliki tipe sesar oblique yaitu kombinasi sesar turun dengan sesar mendatar dengan panjang sesar $=24.54 \mathrm{~km}$ dan lebar rupture $=8.51 \mathrm{~km}$. Daerah dugaan sesar 2 dan 3 memiliki tipe yang sama yakni sesar oblique, yang merupakan kombinasi sesar naik dan sesar mendatar dengan panjang sesar $27.54 \mathrm{~km}$ dan lebar rupture $=9.22 \mathrm{~km}$. Sedangkan untuk sesar 3 dengan panjang sesar $24.54 \mathrm{~km}$ dan lebar rupture $=8.51 \mathrm{~km}$. Dalam analisis bola fokus ini, sesar Gorontalo tidak terdeteksi keberadaannya. Diperkirakan sesar ini tidak aktif secara seismik.

Berdasarkan hasil analisis mekanisme bola fokus kejadian gempa bumi di wilayah daratan Gorontalo, di wilayah tengah daratan Gorontalo, ditemui bola fokus yang arah strike tidak sesuai dengan peta geologi. Metode ini mendeteksi keberadaan dugaan sesar aktif yang tidak terdeteksi pada peta geologi.

\section{Daftar Pustaka}

[1] Afnimar, 2009. Seismologi, Penerbit ITB. Bandung

[2] Ibrahim, Gunawan, dan Subardjo. 2005. Pengetahuan Seismologi. Badan Meteorologi dan Geofisika.Jakarta

[3] Abidin, H. Z. et al, 2009. Deformasi Koseismik dan Pascaseismik Gempa Yogyakarta 2006 dari Hasil Survei GPS Jurnal Geologi Indonesia Vol. 4 No. 4 December 2009.

[4] Wells, D. L. Dan K. J. Coopersmith, 1994. New empirical Relationship among Magnitude, Rupture Lenght, Rupture Area, and Surface Displacement, Bulletin of Seismological Society Of America vol.84 No.4 pp 974-1002.

[5] Pasau, G. dan A. Tanauma. 2011. Pemodelan Sumber Gempa di Wilayah Sulawesi Utara sebagai Upaya Mitigasi Bencana Gempa bumi.Jurnal IImiah Sains 11(2). 